\title{
A facile approach for the synthesis of indenoimidazole derivatives and their supramolecular study
}

\author{
RAZA MURAD GHALIB ${ }^{\mathrm{a}, \mathrm{c}, *}$, SAYED HASAN MEHDI $^{\mathrm{b}}$, ROKIAH HASHIM $^{\mathrm{c}}$, \\ SOLHE F ALSHAHATEET ${ }^{d}$ and OTHMAN SULAIMAN ${ }^{c}$ \\ ${ }^{a}$ Department of Chemistry, Faculty of Sciences and Arts-Khulais, University of Jeddah, P.O. Box-355, \\ Postal Code-21921, Jeddah, Kingdom of Saudi Arabia \\ ${ }^{b}$ Department of Chemistry, S P G College, University of Lucknow, Lucknow, Uttar Pradesh 226 020, India

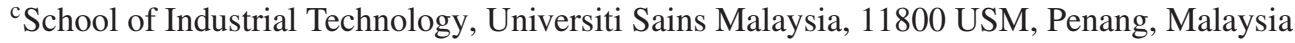 \\ ${ }^{\mathrm{d} D e p a r t m e n t ~ o f ~ C h e m i s t r y, ~ M u t a h ~ U n i v e r s i t y, ~ P . O . ~ B O X ~ 7, ~ M u t a h ~ 61710, ~ K a r a k, ~ J o r d a n ~}$ \\ e-mail: raza2005communications@gmail.com
}

MS received 15 September 2015; revised 17 July 2016; accepted 17 September 2016

\begin{abstract}
The structures of the title Indeno-imidazole compounds, have been determined by FTIR, NMR, mass and single crystal X-ray diffraction. 3a,8a-Dihydroxy-1-phenyl-1,3,3a,8a-tetrahydro-indeno[1,2d]imidazole-2,8-dione (1) crystallizes in the monoclinic, space group $P 2_{1} / c$ with a $=12.0913(7) \AA, b=$ 5.7204(3) $\AA, \mathrm{c}=19.8168(11) \AA, \alpha=90.00^{\circ}, \beta=103.6650(10)^{\circ}, \gamma=90.00^{\circ}, \mathrm{V}=1331.87(13) \AA^{3}, \mathrm{Z}=4$; while 3a,8a-Dihydroxy-1-phenyl-2-thioxo-2,3,3a,8a-tetrahydro-1H-indeno[1,2-d]imidazol-8-one (2) crystallizes in the monoclinic, space group $P 2_{1} / c$ with $\mathrm{a}=11.0101(5) \AA, \mathrm{b}=6.8421(3) \AA, \mathrm{c}=21.1243(9) \AA$, $\alpha=90.00^{\circ}, \beta=110.771(2)^{\circ}, \gamma=90.00^{\circ}, V=1487.91(11) \AA^{3}, Z=4$. Solid-state crystal structures of compounds $\mathbf{1}$ and $\mathbf{2}$ are presented here in terms of crystal engineering and supramolecular chemistry. Replacement of oxygen atom of compound $\mathbf{1}$ by sulfur atom in compound $\mathbf{2}$ forced compound $\mathbf{2}$ to hold water molecules and formed the hydrated form.
\end{abstract}

Keywords. Supramolecular assemblies; hydrated structure; intermolecular non-covalent interactions.

\section{Introduction}

Ninhydrin (1,2,3-indanetrione monohydrate) has a versatile role in organic synthesis. C-2 position of ninhydrin is more reactive towards nucleophiles and undergoes acid catalyzed cyclization reactions with various urea derivatives to give indano-imidazoles. Indano-imidazoles are heterocyclic organic compounds of wide biological importance. ${ }^{1,2}$ Chen et al., synthesized a series of novel hybrid Indeno[5,6-b]furan-imidazole compounds by the reactions of tricyclic indeno[5,6b]furan and imidazole and evaluated toxicity in vitro against a panel of human tumor cell lines. Their results suggest that the existence of benzimidazole ring and substitution of the imidazolyl-3-position with a naphthylacyl group were vital for modulating cytotoxic activity. ${ }^{3}$ Sarkarzadeh et al., synthesized imidazolebased indeno[1,2-b]quinoline-9,11-dione derivatives and evaluated antiproliferative activity by using MTT assay. Their results suggested that some of the imidazolesubstituted indeno[1,2-b]quinoline-9,11-dione compounds may act as efficient anticancer agents in vitro,

*For correspondence emphasizing their potential role as a source for rational design of potent anti-proliferative agents. ${ }^{4}$ Devi in 2012 synthesized ninhydrin guanidinium chloride as 3a,8b-dihydroxy-4-oxo- $1 \mathrm{H}, 2 \mathrm{H}, 3 \mathrm{H}, 3 \mathrm{aH}, 4 \mathrm{H}, 8 \mathrm{bH}$-indeno [1,2-d]imidazolidin-2-iminium chloride. The structure was confirmed by single crystal X-ray and spectral analysis. ${ }^{5}$ Shapiro reported cyclization reactions of ninhydrin with aromatic amines and ureas to give indanoimidazole derivatives. ${ }^{6}$ Hossaini in 2013 introduced a facile, green and efficient method for synthesis of new class of imidazole derivatives via one-pot condensation of primary amines with trichloroacetonitrile and ninhydrin in water. ${ }^{7}$ In an important study, Chatterjie reported the synthesis of imidazole derivatives with strong anticonvulsive activity against seizures induced by pentylenetetrazole and low toxicity, by the cyclocondensation of ninhydrin with 1-propyl1-alkyl-, 1-butyl-, 1-phenylurea, 6-aminouracil, and 1,3-dimethyl-6-aminouracil. ${ }^{8}$ Our previous studies, reported synthesis, crystal structures, supramolecularity of several indenoimidazoles with antimicrobial and cholinesterase enzymes inhibitory activities., ${ }^{9,20,22}$ The title adducts have been synthesized in minimum time (15 min) with maximum yields $(95 \%)$. 
Nowadays, supramolecular chemists are interested in design, synthesis, and characterization of supramolecular assemblies, which have the ability to work as functional materials. Understanding the intermolecular non-covalent interactions that are present in the crystal structure of a given solid compound will lead to a greater understanding of its useful properties. ${ }^{10-18}$ This understanding is important and crucial to understand, hopefully, biological processes. ${ }^{19-34}$ In this paper, compounds $\mathbf{1}$ and $\mathbf{2}$ were prepared by the cyclocondensation of ninhydrin with 1-phenylurea and 1-phenyl thiourea. Furthermore, their solid-state structures and the supramolecular behavior were determined, analyzed and presented in terms of supramolecular chemistry and crystal engineering concepts.

\section{Experimental}

\subsection{Instrument and chemicals}

Ninhydrin, 1-phenylurea and 1-phenylthiourea were purchased from Aldrich (Germany) and used as received. Chloroform, ethanol and glacial acetic acid were obtained from Merck (Germany) and used without further purification. All other reagents used were of analytical grade. The melting points were taken on Thermo Fisher digital melting point apparatus of IA9000 series and are uncorrected. FTIR spectra were measured by direct transmittance by means of the $\mathrm{KBr}$ pellet technique using a Nicolet Impact 400 FTIR spectrometer equipped with a DTGS detector. High resolution ESI-MS were recorded on a Finnigan TSQ Quantum Ultra AM Thermo Electron. ${ }^{1} \mathrm{H}$ NMR spectra were recorded on Bruker Avance $500 \mathrm{MHz}$ with TMS as an internal standard and $125 \mathrm{MHz}$ for ${ }^{13} \mathrm{C}$ NMR. Spectra were recorded in DMSO-d6. Elemental analysis was performed on a Perkin Elmer 2400 Series II Elemental CHNS analyzer.

2.2 Synthesis of 3a,8a-Dihydroxy-1-phenyl-1,3,3a,8atetrahydro-indeno[1,2-d]imidazole-2,8-dione (1)

A mixture of ninhydrin (1.78 g) and phenylurea (1.36 g) in molar ratio 1:1 were well-dissolved in acetic acid and then heated at $100^{\circ} \mathrm{C}$ over water bath for $15 \mathrm{~min}$. The solvent was removed by using rotary evaporator at low pressure to give the solid product, which was then crystallized from ethanol-chloroform $(1: 1 \mathrm{v} / \mathrm{v})$ mixture to give the translucent crystals of title compound (Scheme 1). Yield: $95 \%$, M.p. $215-217^{\circ} \mathrm{C}$. IR (KBr): $v_{\max } 3481,3260,3062,1961,1722,1685,1596$, 1495, 1422, 1290, 1211, 1178, 1135, 1055, 932, 905,

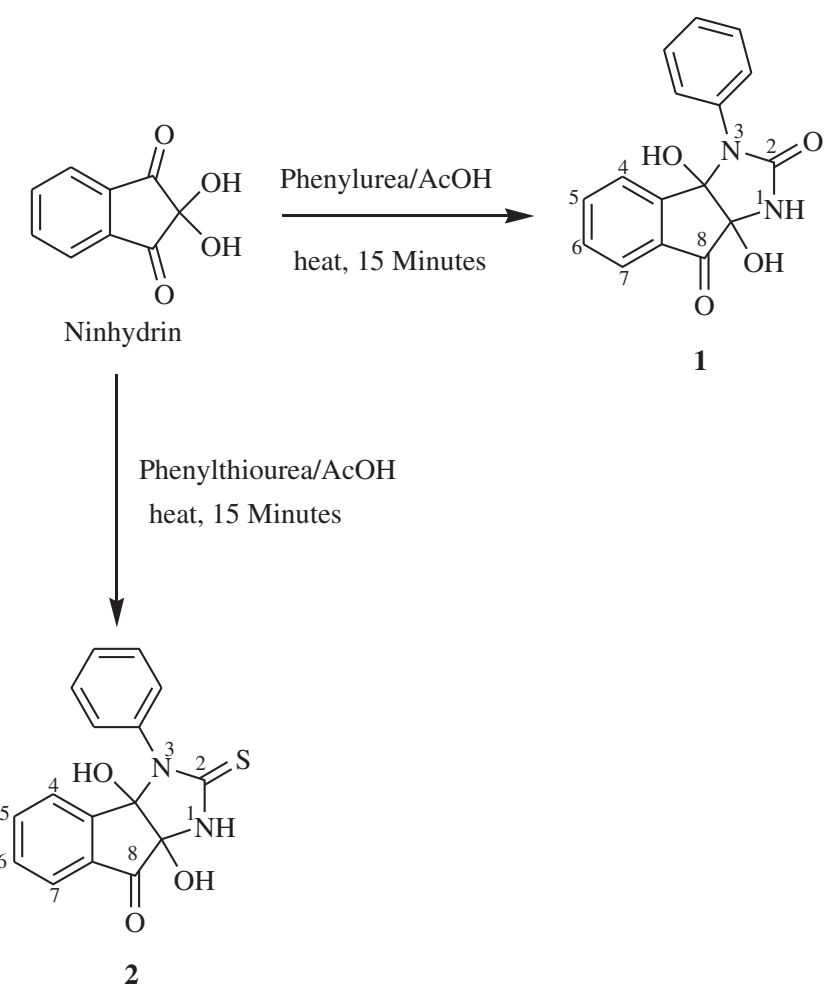

Scheme 1. Synthetic route for derivatives $\mathbf{1}$ and $\mathbf{2}$.

844, 763, 729, 693, $653 \mathrm{~cm}^{-1} .{ }^{1} \mathrm{H}$ NMR (DMSO- $d_{6}$, $500 \mathrm{MHz}$ ): $\delta 3.40$ (br s, $1 \mathrm{H}, \mathrm{N}-\mathrm{H}), 7.02$ (br s, $1 \mathrm{H}$, -O-H), 6.80-7.83 (m, 9H, Aromatic), 8.55 (br s, 1 $\mathrm{H},-\mathrm{O}-\mathrm{H})$ ppm (Figure $\mathrm{S} 1$ in Supplementary Information). ${ }^{13} \mathrm{C}$ NMR (DMSO- $\left.d_{6}, 125 \mathrm{MHz}\right): \delta 85.2,90.1$, 123.8, 124.8, 126.5, 128.1 (2C), 128.4 (2C), 130.4, 132.3, 135.9, 136.1, 149.2, $154.7(\mathrm{C}=\mathrm{O}), 197.5(\mathrm{C}=\mathrm{O})$ ppm (Figure S2 in SI). HR ESI (MS): $m / z 297.1341$ $[\mathrm{M}+\mathrm{H}]^{+}, 12.6 \% ; 296.0368[\mathrm{M}]^{+}, 61 \%$. Elemental anal. Calcd. (\%) for $\mathrm{C}_{16} \mathrm{H}_{12} \mathrm{~N}_{2} \mathrm{O}_{4}$ : C, 64.86; H, 4.08; N, 9.46; O, 21.60. Found (\%): C, 64.73; H, 4.05; N, 9.41; O, 21.51 .

2.3 Synthesis of 3a,8a-Dihydroxy-1-phenyl-2-thioxo-2, 3,3a,8a-tetrahydro-1H-indeno[1,2-d]imidazol-8-one (2)

Compound 2 was synthesized by following abovementioned method except that phenylthiourea $(1.52 \mathrm{~g})$ was used in place of phenylurea (Scheme 1). The reaction mixture was dried by using rotary evaporator at low pressure to give the solid product which was then recrystallized from alcohol-chloroform $(1: 1 \mathrm{v} / \mathrm{v}) \mathrm{mix}-$ ture to give transparent crystals of the title compound 2 (Scheme 1). Yield: 95\%, M.p. 256-268 ${ }^{\circ}$ C. IR (KBr): $v_{\max } 3582$, 3408, 3051, 2000, 1963, 1732, 1600, 1459, 1212, 1112, 1019, 968, 927, 902, 809, 749, 729, 711, $697,658 \mathrm{~cm}^{-1} .{ }^{1} \mathrm{H}$ NMR (DMSO- $d_{6}, 500 \mathrm{MHz}$ ): $\delta 3.40$ (br s, $1 \mathrm{H}, \mathrm{N}-\mathrm{H}), 6.69-7.96$ (m, 9H, aromatic), 10.13 
(br s, $1 \mathrm{H},-\mathrm{O}-\mathrm{H}$ ), 10.38 (br s, $1 \mathrm{H},-\mathrm{O}-\mathrm{H}$ ) ppm (Figure S3). ${ }^{13} \mathrm{C}$ NMR (DMSO- $d_{6}, 125 \mathrm{MHz}$ ): $\delta 88.4$, $92.2,123.8,125.2,127.2,128.2$ (2C), 130.9 (2C), 132.4, 136.4, 137.1, 148.5, 150.6, $178.6(\mathrm{C}=\mathrm{S}), 195.3$ $(\mathrm{C}=\mathrm{O}) \mathrm{ppm}$ (Figure S4). HR ESI (MS): $m / z 313.1242$ $[\mathrm{M}+\mathrm{H}]^{+}, 12.3 \% ; 312.0459[\mathrm{M}]^{+}, 60.9 \%$. Elemental anal. Calcd (\%) for $\mathrm{C}_{16} \mathrm{H}_{12} \mathrm{~N}_{2} \mathrm{O}_{3} \mathrm{~S}: \mathrm{C}, 61.53 ; \mathrm{H}, 3.87 ; \mathrm{N}$, 8.97; O, 15.37; S, 10.27. Found (\%): C, 61.46; H, 3.69; $\mathrm{N}, 8.83 ; \mathrm{O}, 15.34 ; \mathrm{S}, 10.19$.

\subsection{Crystal structure determination}

Reflection data were measured at $293 \mathrm{~K}$ with a Bruker APEX2 CCD diffractometer in $\theta / 2 \theta$ scan mode using graphite monochromated molybdenum radiation $\left(\lambda 0.7107 \mathrm{~A}^{\circ}\right)$. SMART was used for collecting frame data, indexing reflection, and determination of lattice parameters. ${ }^{35}$ SAINT was used for integration of intensity of reflections and scaling. ${ }^{35}$ A semi-empirical absorption correction was applied using the program SADABS. ${ }^{36}$ The structure was solved by direct methods using the program SHELXS. ${ }^{37}$ The refinement and all further calculations were carried out using the program SHELXL. ${ }^{37}$ The $\mathrm{H}$-atoms were included in calculated positions and treated as riding atoms using SHELXL default parameters. The non-H atoms were refined anisotropically, using weighted full-matrix least-squares on $\mathrm{F}^{2}$. Crystallographic data (cif) of the titled compounds $\mathbf{1}$ and $\mathbf{2}$ have been deposited with the Cambridge Structural Data Centre (CCDC) with reference numbers $(1042090,1042091)$. The crystallographic parameters of crystal structure of $\mathbf{1}$ and $\mathbf{2}$ are presented in Table 1.

\subsection{Refinement special details}

Refinement of $\mathrm{F}^{2}$ was performed against all reflections. The weighted R-factor (wR) and goodness of fit $\mathrm{S}$ are based on $\mathrm{F}^{2}$, conventional R-factor (R) are based on $\mathrm{F}$, with $\mathrm{F}$ set to zero for negative $\mathrm{F}^{2}$. The threshold expression of $\mathrm{F}^{2}>2 \operatorname{sigma}\left(\mathrm{F}^{2}\right)$ is used only for calculating $\mathrm{R}$-factors (gt), etc., and is not relevant to the choice of reflections for refinement. R-factors based on $\mathrm{F}^{2}$ are statistically about twice as large as those based on F, and $\mathrm{R}$-factors based on all data will be even larger.

\section{Results and Discussion}

3.1 Structural Study of 3a,8a-Dihydroxy-1-phenyl-1,3, 3a,8a-tetrahydro-indeno[1,2-d]imidazole-2,8-dione (1)

X-ray quality crystals of compound $\mathbf{1}$ were obtained by direct crystallization of $\mathbf{1}$ from ethanol-chloroform $(1: 1 \mathrm{v} / \mathrm{v})$ solvent mixture. Slow evaporation of the solvent has led to nice block-colorless crystals. Compound 1 crystallizes in the monoclinic space group $P 2_{1} / c$

Table 1. Numerical details of the solution and refinement of the crystal structures of compounds $\mathbf{1}$ and $\mathbf{2}$.

\begin{tabular}{lcc}
\hline Compound & $\mathbf{1}$ & $\mathbf{2}$ \\
\hline Formula & $\mathrm{C}_{16} \mathrm{H}_{12} \mathrm{~N}_{2} \mathrm{O}_{4}$ & $\left(\mathrm{C}_{16} \mathrm{H}_{12} \mathrm{~N}_{2} \mathrm{O}_{3} \mathrm{~S}\right) .\left(\mathrm{H}_{2} \mathrm{O}\right)$ \\
Formula mass & 296.28 & 330.35 \\
Space group & $P 2_{1} / c$ & $P 21 / c$ \\
$a / \AA$ & $12.0913(7)$ & $11.0101(5)$ \\
$b / \AA$ & $5.7204(3)$ & $6.8421(3)$ \\
$c / \AA$ & $19.8168(11)$ & $21.1243(9)$ \\
$\alpha /{ }^{\circ}$ & 90 & 90 \\
$\beta /{ }^{\circ}$ & $103.6650(10)$ & $110.771(2)$ \\
$\gamma /{ }^{\circ}$ & 90 & 90 \\
$V / \AA^{3}$ & $1331.87(13)$ & $1487.91(11)$ \\
$T / \mathrm{K}$ & $293(2)$ & $293(2)$ \\
$Z, Z^{\prime}$ & 4,0 & 4,0 \\
$F 000$ & 616 & 688 \\
$D_{\text {calc. }} / \mathrm{g} \mathrm{cm}{ }^{-3}$ & 1.478 & 1.475 \\
Radiation, $\lambda / \AA$ & $M o K \alpha, 0.7107$ & $\mathrm{MoK} \alpha, 0.7107$ \\
$\mathrm{Scan}$ mode & $\theta / 2 \theta$ & $\theta / 2 \theta$ \\
$2 \theta \mu_{\min }-2 \theta \mu_{\max } /{ }^{\circ}$ & $3.04-32.61$ & $1.98-36.78$ \\
Criterion for obs. ref. & $I / \sigma(I)>2$ & $I / \sigma(I)>2$ \\
$R=\sum^{m}|\Delta F| / \sum^{m}\left|F_{\mathrm{o}}\right|$ & 0.0457 & 0.0471 \\
$R_{w}=\left[\sum^{m} w|\Delta F|^{2} / \sum^{m} w\left|F_{\mathrm{o}}\right|^{2}\right]^{1 / 2}$ & 0.1240 & 0.1347 \\
$s=\left[\sum^{m} w|\Delta F|^{2} /(m-n)\right]^{1 / 2}$ & 1.034 & 1.056 \\
\hline
\end{tabular}


with four molecules in the asymmetric unit. Labeled molecular structure of $\mathbf{1}$ including thermal displacement ellipses (50\% probability) is shown in Figure 1.

Molecular structure of $\mathbf{1}$ contains two different types of carbonyl groups; cyclic amide (lactam) and aromatic cyclic ketone. Both groups are totally different in terms of bond length, strength, and angle. Shorter and stronger carbon-oxygen double bond $(\mathrm{C} 3-\mathrm{O} 1=1.209 \AA$ and $\mathrm{C} 2-\mathrm{C} 3-\mathrm{C} 4$ bond angle of $108.04^{\circ}$ ) is detected for the cyclic ketone compared to the cyclic amide $(\mathrm{C} 1$ $\mathrm{O} 4=1.240 \AA$ and N1-C1-N2 bond angle of $109.04^{\circ}$ ). Strong intermolecular non-covalent interactions are observed between molecules of $\mathbf{1}$ such as hydrogen

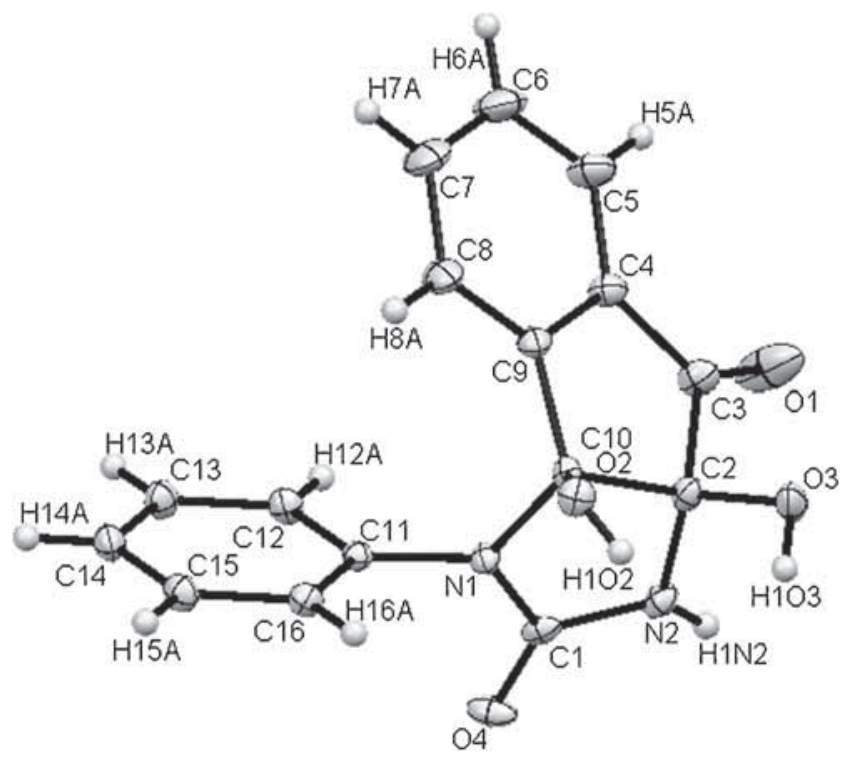

Figure 1. Molecular structure of 1. Thermal ellipsoids are presented in $50 \%$ probability.

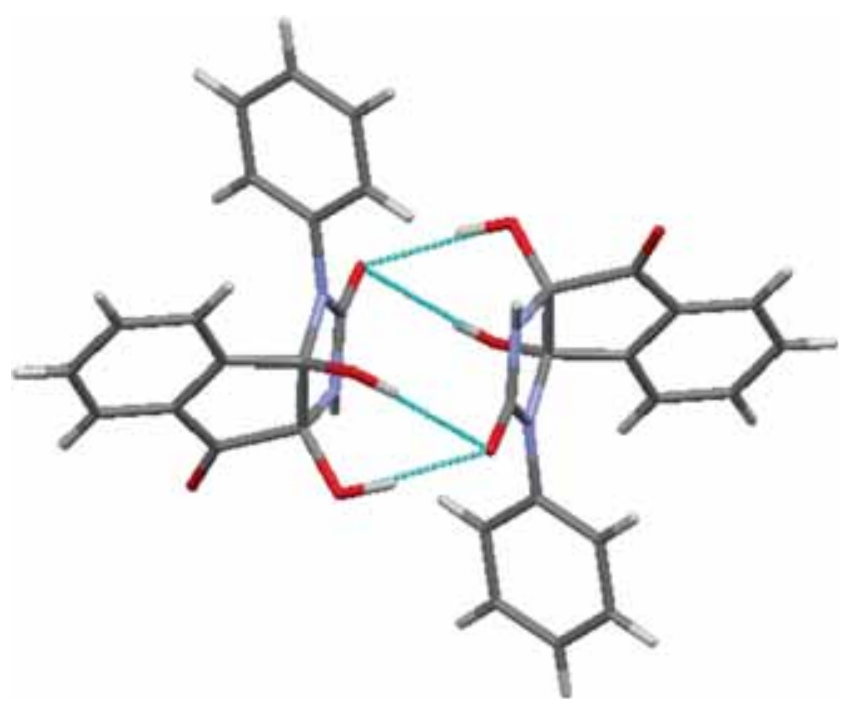

Figure 2. Strong hydrogen bonding which led to centrosymmetric dimer constructed from two molecules of $\mathbf{1}$. bond. Centrosymmetric dimer is formed between two molecules of $\mathbf{1}$ in which oxygen atom $(\mathrm{O} 4)$ of the cyclic ketone carbonyl group of one molecule is bifurcating with the hydrogen atoms of the two hydroxyl groups of another molecule of $\mathbf{1}$ (H1O3 and H1O2) with a contact distances of $1.874 \AA$ and $2.234 \AA$, respectively as shown in Figure 2.

Another edge-edge motif interaction is observed in the crystal packing of $\mathbf{1}$, in which two molecules are interacting through $\mathrm{O} 4$ and $\mathrm{H} 1 \mathrm{~N} 2$ of each molecule to form hydrogen-bonded centrosymmetric dimer with a contact distance of 2.161 Á as shown in Figure 3.

In addition to the above two centrosymmetric dimers, strong hydrogen bonds are connected between two

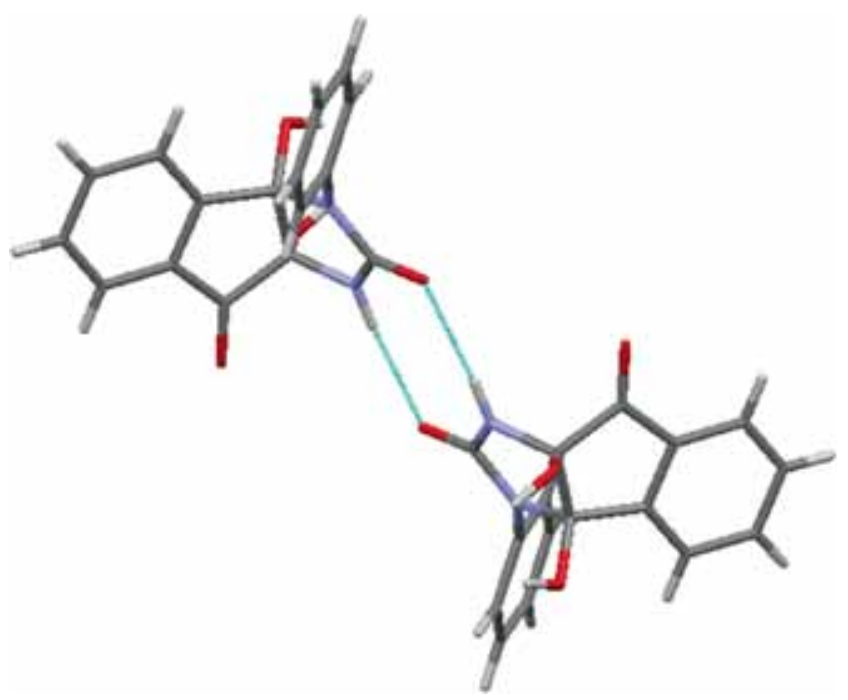

Figure 3. Edge-edge hydrogen-bonded centrosymmetric dimer of two molecules of $\mathbf{1}$ with a contact distance of $2.161 \AA$ Á.

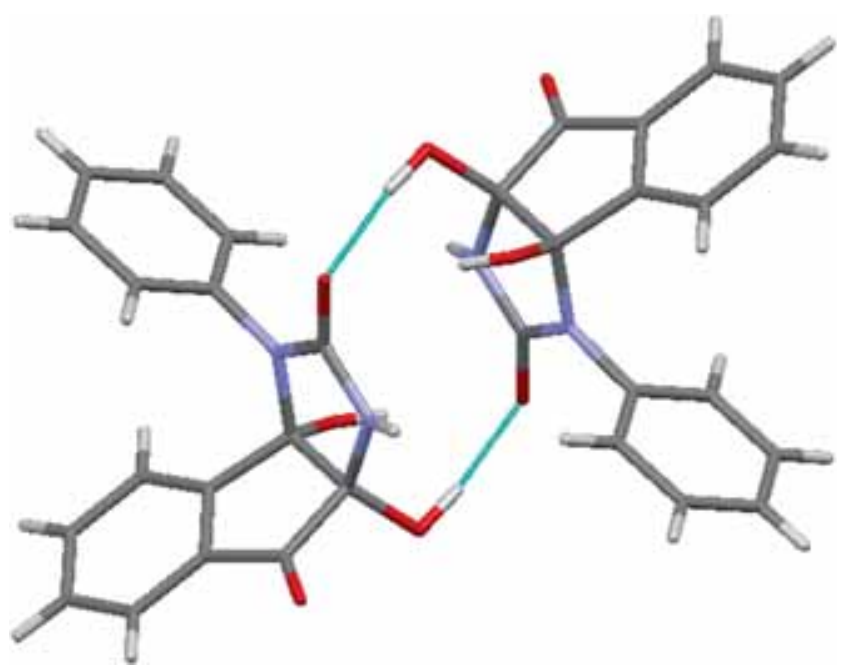

Figure 4. Hydrogen-bonded centrosymmetric dimer between two molecules of $\mathbf{1}$ with a contact distance of $1.874 \AA$ Á. 
molecules of $\mathbf{1}$ to produce a centrosymmetric dimer through the interactions between $\mathrm{H} 1 \mathrm{O} 3$ and $\mathrm{O} 4$ with a contact distance of $1.874 \AA$ Á (Figure 4). Other types of intermolecular non-covalent interactions such as, nitrogen-nitrogen (3.443 ̊̊), nitrogen-hydrogen (2.993 Á), nitrogen-oxygen (2.972 Á), and oxygen-oxygen (2.808 Á) were observed and proved to have strong influence on crystal packing of compound $\mathbf{1}$.

\subsection{Structural Study of 3a,8a-Dihydroxy-1-phenyl-2-} thioxo-2,3,3a,8a-tetrahydro-1H-indeno[1,2-d]imidazol8-one (2)

X-ray quality crystals of compound were obtained by direct crystallization of $\mathbf{2}$ from, ethanol-chloroform $(1: 1 \mathrm{v} / \mathrm{v})$ solvent mixture. Slow evaporation of the solvent has led to nice plates of colorless crystals. Compound 2 crystallizes in the monoclinic space group $P 2_{1} / c$ to produce a hydrated crystal structure with a molecular formula of $\left(\mathrm{C}_{16} \mathrm{H}_{12} \mathrm{~N}_{2} \mathrm{O}_{3} \mathrm{~S}\right) \cdot\left(\mathrm{H}_{2} \mathrm{O}\right)$. Labeled hydrated molecular structure of $\mathbf{2}$ including thermal displacement ellipses (50\% probability) is shown in Figure 5. In addition, the asymmetric unit contains four molecules of $\mathbf{2}$ and four water molecules as shown in Figure 6.

Normally, any slight change in the molecular structure of a given solid compound will lead to a great change in its supramolecular behavior. In our case, the only difference in the molecular structure between $\mathbf{1}$ and $\mathbf{2}$ is that sulfur atom is replaced by oxygen atom of the carbonyl group of the cyclic amide (lactam) to produce a thia-lactam derivative. This replacement has forced compound $\mathbf{2}$ to include water molecules into its crystal structure to form a host-guest complex (hydrate). Crystal structure analyses of compound $\mathbf{2}$ revealed that longer and weaker carbon-oxygen double bond $(\mathrm{C} 2-\mathrm{O} 1=1.223 \AA$ and $\mathrm{C} 1-\mathrm{C} 2-\mathrm{C} 3$ bond angle of $107.99^{\circ}$ ) exists in the molecular structure of 2 compared to 1. As expected, lactam carbon-sulfur double bond has longer and weaker bond $(\mathrm{C} 10-\mathrm{S} 1=1.673 \AA$ and N1-C10-N2 bond angle of $108.74^{\circ}$ ) than the lactam carbon-oxygen double bond of 1 . Different types of

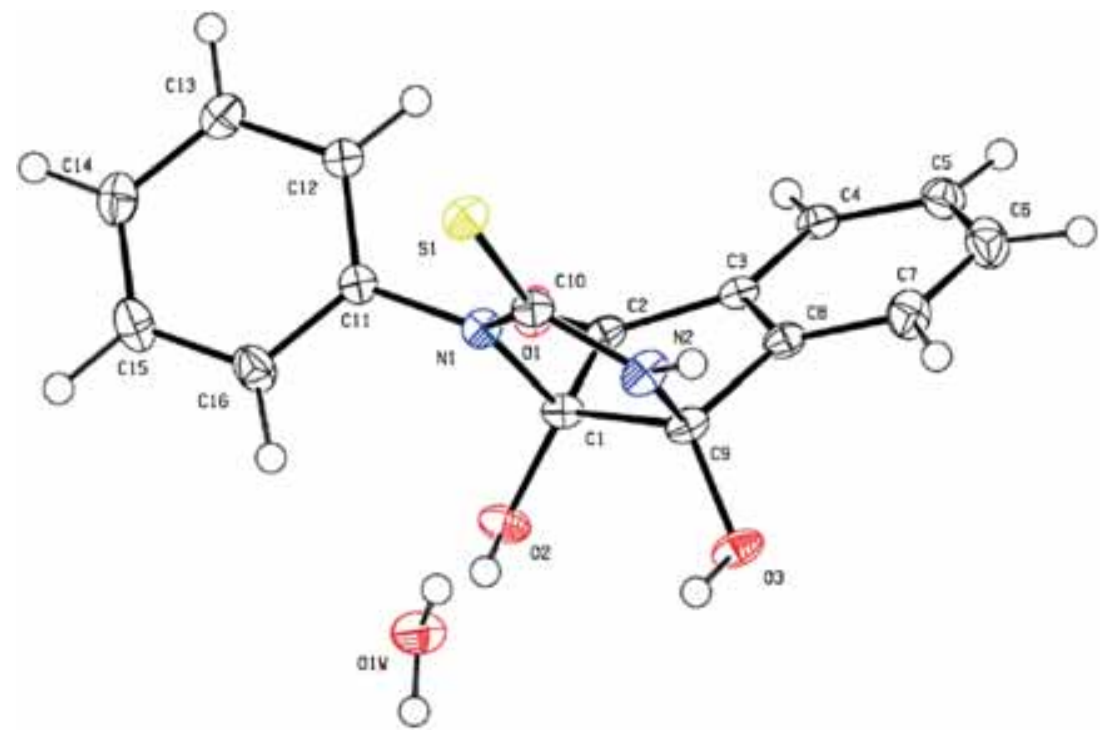

Figure 5. ORTEP plot of the hydrated crystal structure of compound $\mathbf{2}$ showing $50 \%$ probability ellipsoids.

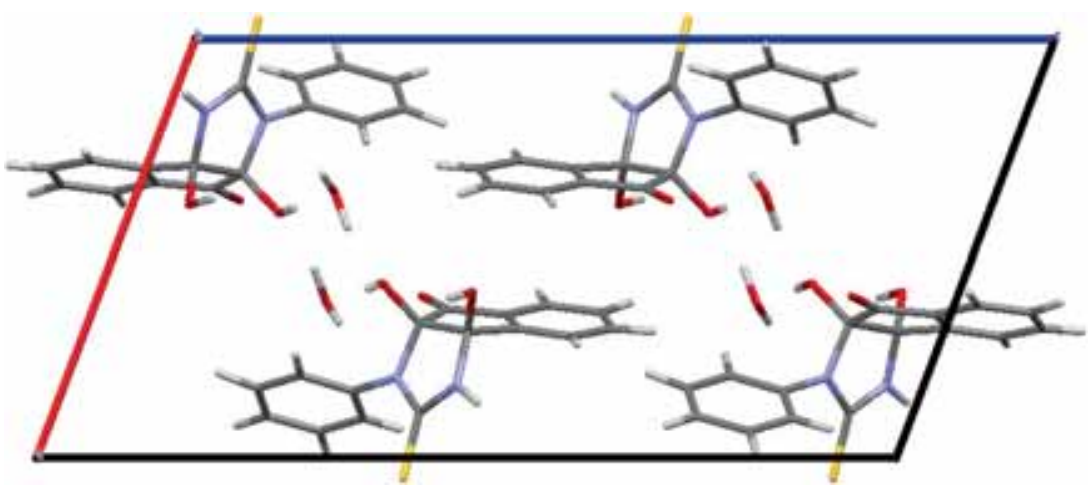

Figure 6. The asymmetric unit of 2. Four molecules of the titled compound together with four water molecules. 


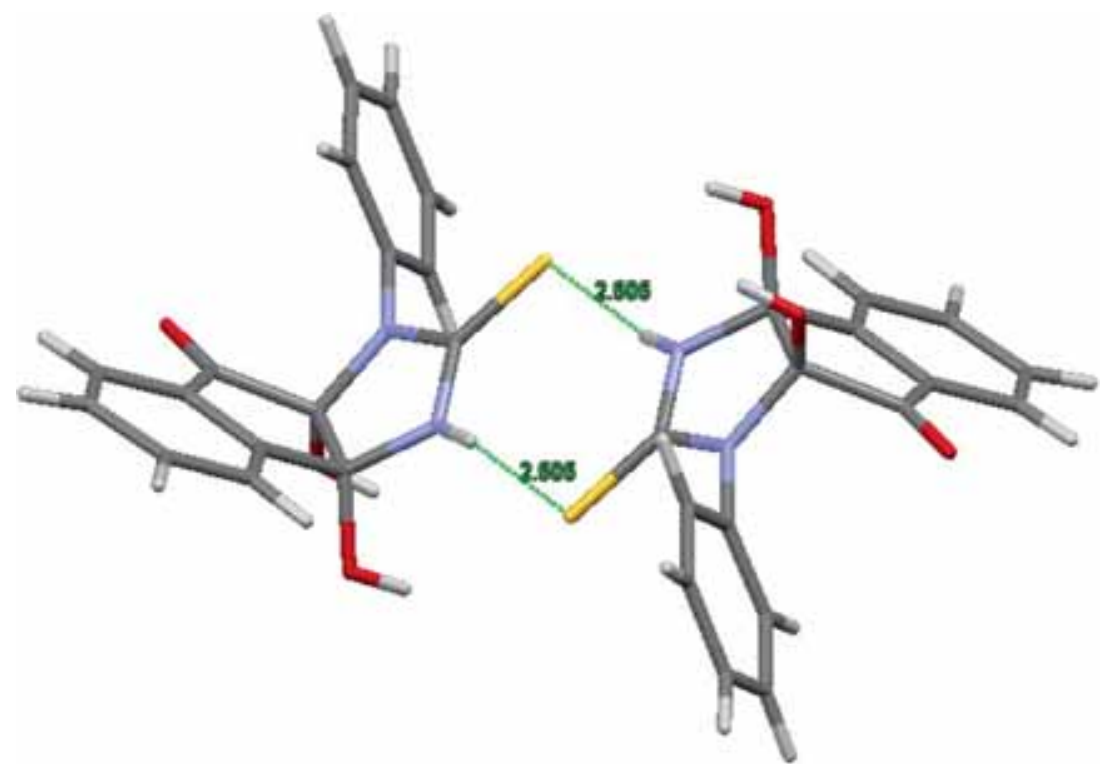

Figure 7. Two molecules of $\mathbf{2}$ interact through sulfur-hydrogen interaction to produce centrosymmetric dimer.

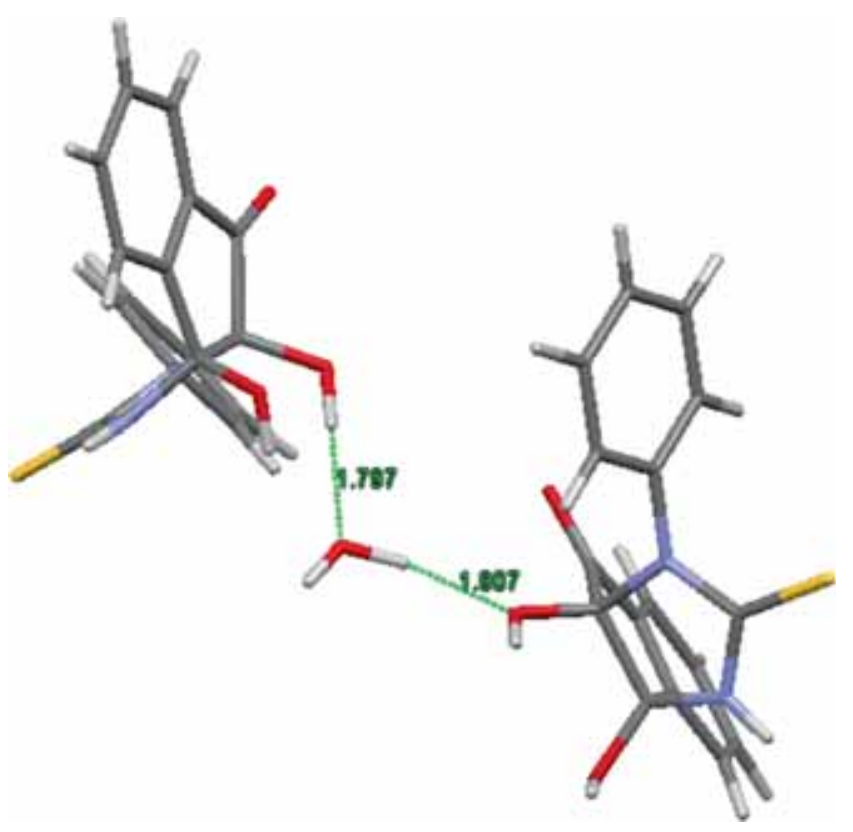

Figure 8. Water molecule acts as both hydrogen bond donor and acceptor as bridge between two molecules of $\mathbf{2}$.

strong intermolecular non-covalent interactions were observed in the crystal structure of the hydrated form of 2. Sulfur atom of the lactam part of one molecule (S1) is interacting with hydrogen atom attached to the nitrogen atom of the lactam part of another molecule (H1N2) to produce a centrosymmetric dimer with a contact distance of $2.505 \AA$ Á (Figure 7).

Water molecules play an important role in stabilizing the crystal packing of $\mathbf{2}$ due to its strong ability to form a hydrogen bond with both hydrogen-bond donor and acceptor. In the crystal structure of $\mathbf{2}$, water molecule bridges two molecules of 2 by acting as hydrogen-bond donor and acceptor at the same time. Oxygen atom of one water molecule $(\mathrm{O} 1 \mathrm{~W})$ is strongly hydrogenbonded to an acidic hydrogen of 2 (H1O2) with a contact distance of $1.797 \AA$ Á. In the same structure, hydrogen atom of the same water molecule (H1W1) is strongly hydrogen-bonded to an oxygen atom of another molecule of $\mathbf{2}(\mathrm{O} 2)$ with a contact distance of $1.807 \AA$ as shown in Figure 8. Weaker intermolecular non-covalent interactions are existed in the crystal structure of the hydrated form of $\mathbf{2}$ such as, S. . S (4.495 ̊́), S. . .N (3.346 ̊́), S. . O (4.4 and 4.36 Á),

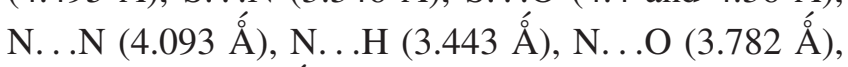
and O. . . O (2.789 ̊́).

\section{Conclusions}

Solid-state crystal structures of compounds $\mathbf{1}$ and $\mathbf{2}$ were successfully determined, analyzed and presented in terms of crystal engineering and supramolecular chemistry. Any slight change in the molecular structure of any given solid compound will lead to a great change in its supramolecularity. In this paper, we replaced oxygen atom of compound $\mathbf{1}$ by sulfur atom to produce compound 2. This replacement forced compound $\mathbf{2}$ to include water molecules and formed the hydrated form. Different types of intermolecular non-covalent interactions were observed and compared for both $\mathbf{1}$ and $\mathbf{2}$. It is still very difficult to predict the crystal structure and the supramolecular behavior even if we know the molecular structure. More work need to done in this area to 
enhance our knowledge and to increase the possibility to predict at least a little bit of the supramolecular behavior of a solid compound in its crystalline form.

\section{Supplementary Information (SI)}

Scanned copies of ${ }^{1} \mathrm{H}$ and ${ }^{13} \mathrm{C}$ spectra of $\mathbf{1}$ and 2 are given in electronic Supporting Information available at www.ias.ac.in/chemsci. CCDC-1042090 and 1042091 contain the supplementary crystallographic data for $\mathbf{1}$ and $\mathbf{2}$. This data can be obtained free of charge at http://www.ccdc.cam.ac.uk/conts/ retrieving.html [or from the Cambridge Crystallographic Data Centre (CCDC), 12 Union Road, Cambridge CB2 1EZ, UK; fax: +44(0)1223-336033; email: deposit@ccdc.cam.ac.uk].

\section{Acknowledgements}

Authors would like to acknowledge University of Jeddah, KSA and Universiti Sains Malaysia (USM) for the research facilities.

\section{References}

1. Roberts L R, Bryans J, Conlon K, McMurray G, Stobie A and Whitlock G A 2008 Bioorg. Med. Chem. Lett. 18 6437

2. Sarra J D and Stephani R A 2000 Med. Chem. Res. 1081

3. Chen W, Yang L-J, Li Y, Wang X-Q, Wang S-J, Wan W-C, Zhang H-B and Yang X-D 2013 Lett. Drug Des. Discov. 10561

4. Sarkarzadeh H, Miri R, Firuzi O, Amini M, RazzaghiAsl N, Edraki N and Shafiee A 2013 Arch. Pharm. Res. 36436

5. Devi T U, Priya S, Selvanayagam S, Ravikumar K and Anitha K 2012 Spectrochim. Acta Mol. Biomol. Spectros. 971063

6. Shapiro R and Chatterjie N 1970 J. Org. Chem. 35447

7. Hossaini Z, Seyfi S, Rostami-Charati F and Ghambarian M 2013 Comb. Chem. High T. Scr. 16788

8. Chatterjie N, Sinha B and Alexander G J 1983 Res. Commun. Chem. Pathol. Pharmacol. 39333

9. Ghalib R M, Hashim R, Mehdi S H, Quah C K and Fun H-K 2011 Acta Cryst. E 67 o1525

10. Hasenknopf B, Lehn J-M, Kneisel B O, Baum G and Fenske D 1996 Angew Chem. Int. Ed. 351838

11. Day A I 2002 Angew. Chem. Int. Ed. 41275

12. Bravo J A 1998 Eur. J. Org. Chem. 19982565
13. Anderson S, Anderson H L, Bashall A, McPartlin M and Sanders J K M 1995 Angew Chem. Int. Ed. 34 1096

14. Freeman W A 1984 Acta Cryst. Sect. B $\mathbf{4 0} 382$

15. Schmitt J-L, Stadler A-M, Kyritsakas N and Lehn J-M 2003 Helv. Chim. Acta 861598

16. Lehn J-M 1993 Science 2601762

17. Lehn J-M 1995 In Supramolecular Chemistry (Weinheim: Wiley-VCH Verlag $\mathrm{GmbH}$ )

18. Gennady V, Oshovsky David N R and Willem V 2007 Angew. Chem. Int. Ed. 462366

19. Alshahateet S F, Bishop R, Craig D C and Scudder M L 2011 Cryst. Growth Des. 114474

20. Ghalib R M, Hashim R, Alshahateet S F, Mehdi S H, Sulaiman O, Chan K-L, Murugaiyah V and Jawad A 2012 J. Chem. Crystallogr. 42783

21. MacNicol D D and Downing G R 1996 In Symmetry in the evolution of host design, in Comprehensive Supramolecular Chemistry, Vol. 6 Solid-state Supramolecular Chemistry: Crystal Engineering D MacNicol, F Toda and R Bishop (Eds.) (Oxford: Pergamon Press) Ch. 14 pp. 421-464

22. Ghalib R M, Hashim R, Alshahateet S F, Mehdi S H, Sulaiman O, Murugaiyah V and Aruldass C A $2011 \mathrm{~J}$. Mol. Struct. 1005152

23. Alshahateet S F, Al-Zereini W A and Alghezawi N M 2011 J. Chem. Crystallogr. 411807

24. Kooli F, Hian P C, Weirong Q, Alshahateet S F and Chen F 2006 J. Porous Mat. 13319

25. Alshahateet S F, Bishop R, Craig D C and Scudder M L 2003 CrystEngComm 3417

26. Alshahateet S F, Bishop R, Craig D C and Scudder M L 2010 Cryst. Growth Des. 101842

27. Alshahateet S F, Bishop R, Scudder M L, Hu C Y, Lau E H E, Kooli F, Judeh Z M A, Chow P S and Tan R B H 2005 CrystEngComm 7139

28. Kooli F, Mainhui L, Alshahateet S F, Chen F and Yinghuai Z 2006 J. Phys. Chem. Solids 67926

29. Alshahateet S F, Bishop R, Craig D C, Kooli F and Scudder M L 2008 CrystEngComm 10297

30. Alshahateet S F, Ong T T, Bishop R, Kooli and Messali M 2006 Cryst. Growth Des. 61676

31. Alshahateet S F, Bishop R, Craig D C, Scudder M L and Ung A T 2001 Struct. Chem. 12251

32. Alshahateet S F, Bhadbhade M M, Bishop R and Scudder M L 2015 CrystEngComm 17877

33. Alshahateet S F, Bhadbhade M M, Bishop R, Craig D C and Scudder M L 2015 CrystEngComm 179111

34. Alshahateet S F 2015 Mol. Cryst. Liq. Cryst. 607169

35. SMART and SAINT 1996 Software Reference Manuals Version 4.0 (Siemens Energy and Automation, Inc., Analytical Instrumentation: Madison, WI)

36. Sheldrick G M 1996 In SADABS (Germany: University of Göttingen)

37. Sheldrick G M 2008 SHELXS and SHELXL Acta Crystallogr. A 64112 